\title{
The challenge of improving visibility in Beijing
}

\author{
Q. H. Zhang, J. P. Zhang, and H. W. Xue \\ Department of Atmospheric and Oceanic Science, School of Physics, Peking University, Beijing, China
}

Received: 18 December 2009 - Published in Atmos. Chem. Phys. Discuss.: 5 March 2010

Revised: 1 August 2010 - Accepted: 17 August 2010 - Published: 24 August 2010

\begin{abstract}
The "Blue Sky Project" was proposed in 1998 to investigate by how much emissions should be reduced to increase blue sky frequency in Beijing, which hosted the Summer Olympics in 2008. This paper focuses on the temporal variation of visibility and its dependence on meteorological conditions and suspended particles at Beijing using the hourly observed visibility data at Beijing Capital International Airport (BCIA) from 1999 to 2007. It has been found that about $47.8 \%$ (24.2\%) of the hours in Beijing are "bad" ("good") hours with visibility below $10 \mathrm{~km}$ (equal or higher than $20 \mathrm{~km}$ ) between 1999 and 2007. Due to the high Relative Humidity ( $\mathrm{RH})$, summer is the season with the lowest mean visibility in a year. Although $\mathrm{PM}_{10}$ index was reported in a decreasing trend (Chan and Yao, 2008), the increase of RH has resulted in a decreasing trend of visibility over BCIA in the summer from 1999 to 2007. To ensure blue sky ("good" visibility) for Olympics 2008, daily mean $\mathrm{PM}_{10}$ index should have been reduced from 81 to 44 . This requires that not only vehicle emissions, but also other emissions should be limited. Observations verify that blue-skyhour rate increased significantly after mean $\mathrm{PM}_{10}$ index was reduced to 53 during Olympics 2008, however, the visibility of 2009 returned to the mean level from 1999 to 2007 during the period 8-24 August. RH (aerosol) contribute 24\% (76\%) of the improvement of visibility during August 2008.
\end{abstract}

\section{Introduction}

Since the end of last century, there has been a growing interest in the connection between air quality and human health effects, such as chronic respiration illness, cancer, and cardiovascular morbidity (Samet et al., 2000; Pope et al., 2002;

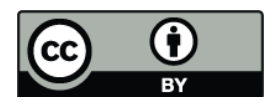

Correspondence to: Q. H. Zhang (qzhang@pku.edu.cn)
Hauck et al., 2004). Visibility may act as an indicator for air quality (Bäumer et al., 2008). Recently, clear sky visibility has been found to decrease over land globally from 1973 to 2007 (Wang et al., 2009). Understanding the temporal variation of the atmospheric visibility and the factors affecting it is important in a mega-city because poor visibility has significance for not only human health but also air and ground transportation.

Beijing hosted 2008 summer Olympics. Atmospheric visibility, as well as air quality, were important factors determining the success of the 2008 Beijing Olympic Games. Measures have been taken to improve the air quality of Beijing, including moving high-polluting industries out of Beijing, replacing coal fuel with natural gas, and phasing out leaded gasoline in recent years. Pollutants such as sulfates and nitrates have been reduced significantly since 1998 (Chan and Yao, 2008), and the $\mathrm{PM}_{10}$ (Aerosol particulate matters having diameters less than $10 \mu \mathrm{m})$ concentration has also been reduced after 2003 (Chan and Yao, 2008). Improvements in visibility have been experienced at UK after the reduction of pollution (Doyle and Dorling, 2002). The Chinese government has planned to increase Blue Sky frequency by limiting vehicle emission during Beijing 2008 Olympics. In this regard, understanding the relationship between visibility and meteorological conditions and aerosols is essential as a first step toward the development of a program to improve visibility in Beijing.

Visibility at a given location is controlled by the physical and chemical properties of the particulate matter and the ambient relative humidity (RH). Numerous studies carried out all over the world indicate that visibility impairment is largely due to the light scattering of ambient aerosols. Concentrations of these aerosols are governed by meteorological conditions and the emission source strength (Sequiera and Lai, 1998; Sloane, 1983, 1984; Lee, 1983; Dayan and Levy, 2005; Tsai, 2005; Vautard, 2009). Qin and Yang (2000) illustrated a clear trend of downward visibility in Beijing during

Published by Copernicus Publications on behalf of the European Geosciences Union. 
1980-1994, using the visibility data at Beijing Local Time 14:00 LT in clear days. Decreasing trend of visibility during 1973-2007 were also detected on the basis of the daily visibility, which was defined by a minimum of four synoptic observations per day from National Climate Data Center (Chang et al., 2009). There is, however, no comprehensive visibility study based on hourly data for recent years in general. This paper focus on the temporal variation of visibility and its relay on meteorological condition and suspended particles, in order to give advice for improving visibility during the Beijing 2008 Olympics. Data are described in Sect. 2, which followed by result and discussion in Sect. 3. Finally, conclusions are given in Sect. 4.

\section{Data descriptions}

In this paper, the hourly operational meteorological data (visibility, temperature, pressure, dew point temperature, $\mathrm{RH}$ ) are used to investigate the temporal variation of visibility and its relationship with the meteorological conditions from 1999 to 2007. The data are provided by the information center of Beijing Capital International Airport (BCIA) after quality control. The visibility observation is obtained manually. The archived weather observations record on an hourly basis is used in the present study. A "good" hour, is defined as the hour with a visibility equal or higher than $20 \mathrm{~km}$ in this study. A "bad" hour is defined as the hour with a visibility lower than $10 \mathrm{~km}$. A "very bad" hour is defined as the hour with a visibility lower than $2 \mathrm{~km}$. In this paper, "blue sky rate" is defined as the occurrence frequency of the "good" hour.

Considering that particles in the fine $(<2.5 \mu \mathrm{m})$ fraction account for $99 \%$ number concentration of the total particles in airborne PM samples in Beijing (Shi et al., 2003), daily mean $\mathrm{PM}_{10}$ data from 2003 to 2007 is used to analyze the correlation between visibility and suspended particles. The daily mean concentrations of $\mathrm{PM}_{10}$, a primary pollutant, in the Beijing city have been presented in the form of the ambient air pollution index (API). The relationships between API and $\mathrm{PM}_{10}$ concentration is given in Table 1. The data obtained from Beijing Environmental Protection Bureau (BJEPB: http://www.bjepb.gov.cn/air2008/Air.aspx) include daily API for 28 surface stations from 2003 to 2009. Unfortunately, not all stations have the complete records of API for 7 years because of some unexpected and historical reasons, for instance, some data are lost, some stations were relocated and some were established after 2006 during this period. In this study, we chose 19 stations with consistent observations from 2003 to 2009 (details are provided by the supplementary material, Table $\mathrm{S} 1$ ). The daily $\mathrm{PM}_{10}$ data is spatially averaged from 19 monitoring stations in the Beijing city (Fig. 1). If there is a day in which API record of more than 3 stations are missing, the day is regarded as an invalid day. Data in an invalid day are not considered in our analysis.

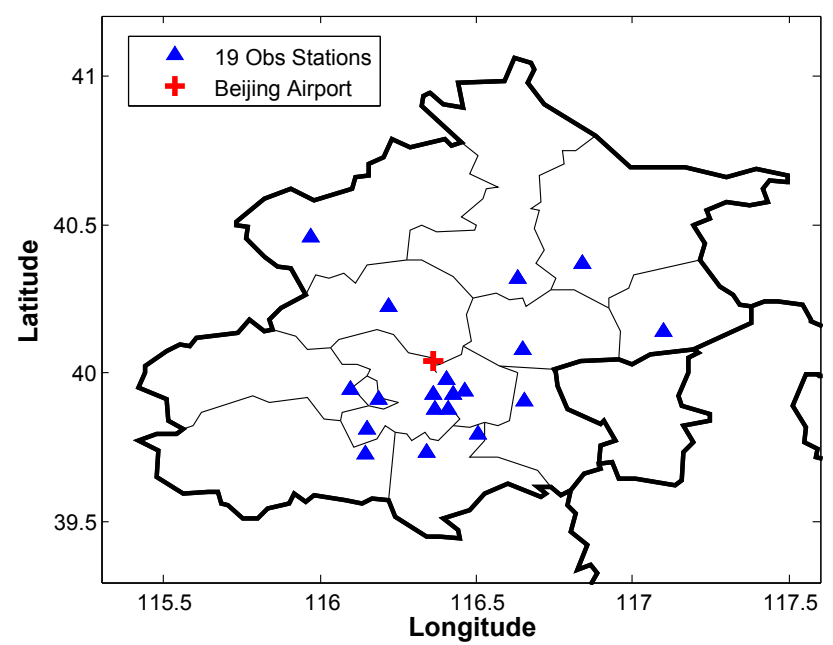

Fig. 1. Locations of the Beijing airport and 19 API observation stations in Beijing.

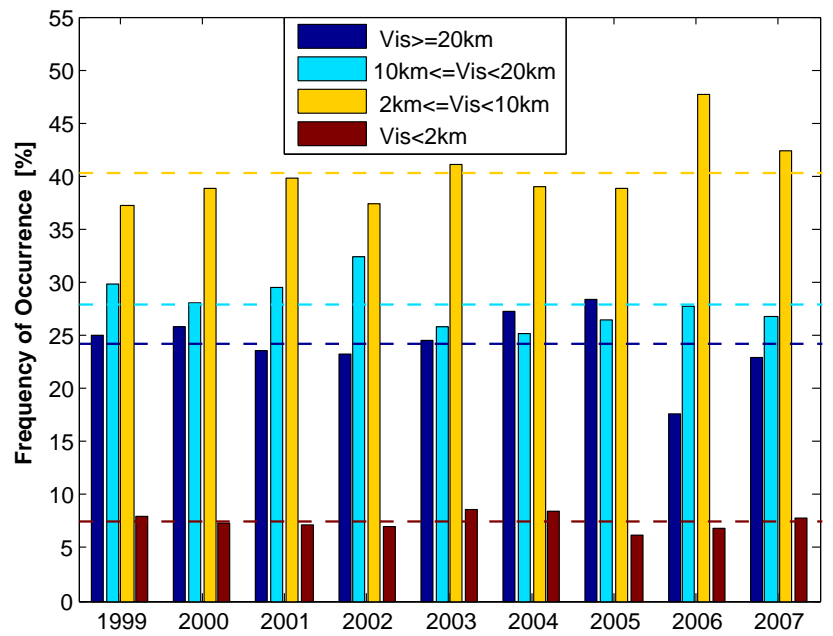

Fig. 2. Occurrence frequency of hourly visibility in different visual ranges from 1999 to 2007. Dashed lines show the 1999-2007 average frequency of visibility in different visual ranges.

In addition, we also calculate the daily mean $\mathrm{RH}$, visibility and $\mathrm{PM}_{10}$ for August from 2003 to 2008.

\section{Results and discussions}

\subsection{Temporal variations of visibility and RH}

Hourly visibility data from 1999 to 2007 are summarized in Fig. 2 according to visual ranges. Only $24.2 \%$ of the hours in Beijing were "good" hours (blue bars and blue dashed line) and about $47.8 \%$ were "bad" hours (including yellow and brown bars and lines) from 1999 to 2007 . The frequency of visibility between $2 \mathrm{~km}$ and $10 \mathrm{~km}$, shown by yellow bars, 
Table 1. The relationships between API and $\mathrm{PM}_{10}$ concentration.

\begin{tabular}{lll}
\hline API & $\mathrm{PM}_{10}$ Conc. $\left(\mu \mathrm{g} \mathrm{m}^{-3}\right)$ & Level of air quality \\
\hline $0-50$ & $0-50$ & Excellent \\
$50-100$ & $50-150$ & Good \\
$100-200$ & $150-350$ & Slight pollution \\
$200-300$ & $350-420$ & Moderate pollution \\
$300-400$ & $420-500$ & Heavy pollution \\
$400-500$ & $500-600$ & Heavy pollution \\
\hline
\end{tabular}

has increased from $37 \%$ in 1999 to $43 \%$ in 2007 . The frequency of "very bad" hours does not have much fluctuation from 1999 to 2007 . This leads to an increase of the frequency of "bad" hours during the years. It should be noted that "very bad" hour in BICA is often influenced by several weather phenomena, such as fog, haze, dust and precipitation. From 1999 to 2007, about $68.7 \%$ of the "very bad" hours are caused by fog. About $27.7 \%, 3.0 \%$ and $0.6 \%$ of them are associated with haze, dust and precipitation, respectively.

Seasonal and diurnal variations of visibility and their trends from 1999 to 2007 are illustrated in Fig. 3. To avoid the influence of precipitation and fog to the visibility observation, the data of precipitation and fog hours are excluded from analysis (Trijonis, 1979; Chen et al., 2003). Summer is the season with the lowest visibility. Mean visibility in summer is generally below $10 \mathrm{~km}$ during the night and morning, and exceeds $10 \mathrm{~km}$ only in the afternoon. Note that July is the "worst" month with a mean visibility of $9.4 \mathrm{~km}$. The mean visibility in August, the month summer Olympics 2008 was held, is $9.8 \mathrm{~km}$ from 1999 to 2007 . For the other seasons, mean visibility generally exceeds $10 \mathrm{~km}$ during the day time, and is lower than $10 \mathrm{~km}$ during the night time. October is the "best" month with a mean visibility of $12.8 \mathrm{~km}$. The monthly variation of RH shown in Fig. 4 reveals that the moisture abundance in summer is responsible for the relatively low visibility.

The lowest visibility of $9.7 \mathrm{~km}$ occurs at 01:00 LT, and the highest visibility, which is $13.7 \mathrm{~km}$, appears at 15:00 LT. The relatively good visibility in the afternoon is mainly because of the high temperature (not shown) from solar heating that reduces the RH (Fig. 4), and in addition, the higher PBL (Planetary Boundary Layer) in the afternoon may provide suitable conditions for vertical mixing of pollutants, leading to better visibility.

On average, the annual mean visibility is decreasing at $-0.13 \mathrm{~km}$ per year from 1999 to 2007 , however the decreasing trend is not significant at $95 \%$ confident level. While there is an obvious decreasing trend of visibility in most months, summer is the main season that contributes to the decrease of annual mean visibility (Fig. 3). The decreasing trend in July is significant at $95 \%$ confidence level. The de-

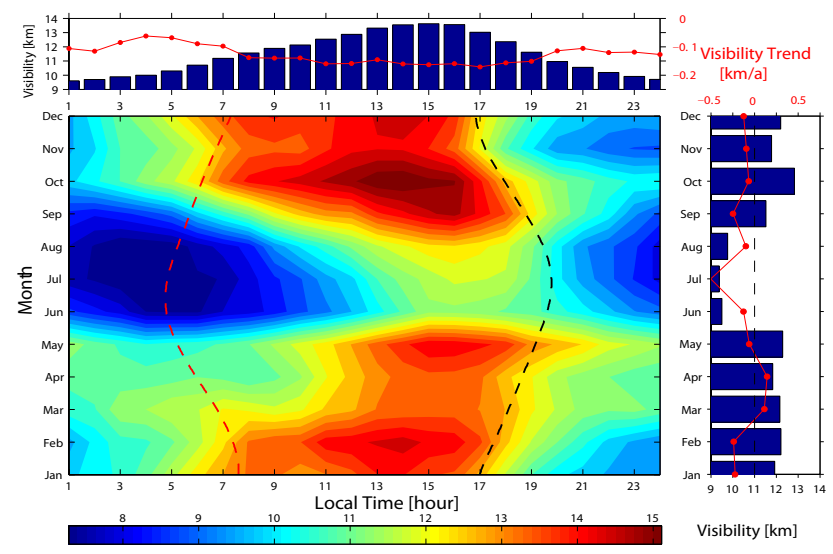

Fig. 3. Visibility distribution in relation to Month and Local Time (filled color). The blue bars at the top (on the right) denote mean visibility over the entire period 1999 to 2007 for each hour (month). The red curves denote visibility trend in BCIA from 1999 to 2007. Red dash line represents sunrise time and black dash line represents sunset time.

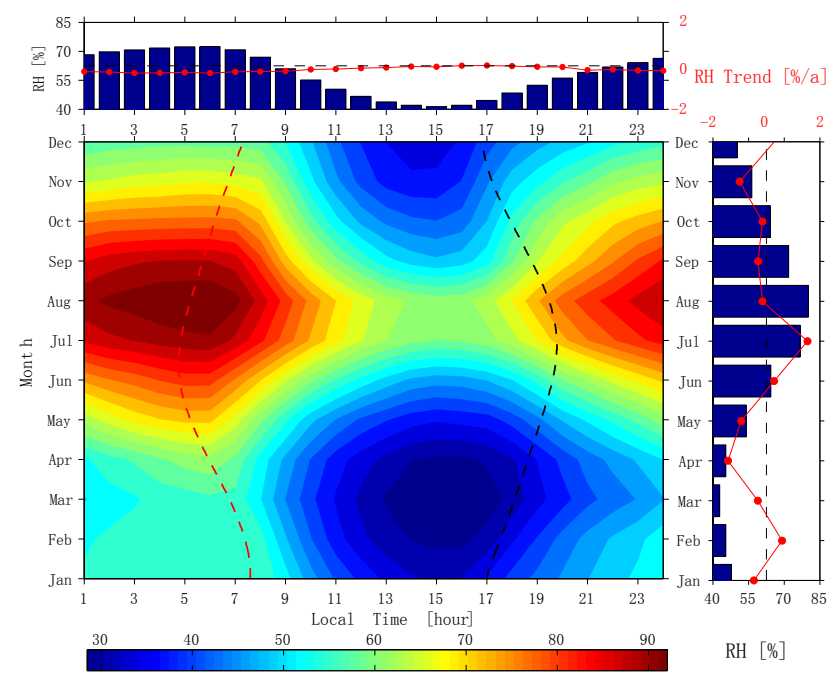

Fig. 4. RH distribution in relation to Month and Local Time (filled color). The blue bars at the top (on the right) denote mean visibility over the entire period 1999 to 2007 for each hour (month). The red curves denote visibility trend in BCIA from 1999 to 2007. Red dash line represents sunrise time and black dash line represents sunset time.

creasing rate peak is about $-0.5 \mathrm{~km}$ per year in July, and it could be explained by the obvious increasing trend of $\mathrm{RH}$ in summer (Fig. 4). The mean visibility trends are negative for every hour and reaches the minimum value of $-0.17 \mathrm{~km}$ per year in the late afternoon (17:00 LT), when a slight increase of RH was found in Fig. 4, although none of them are significant. 


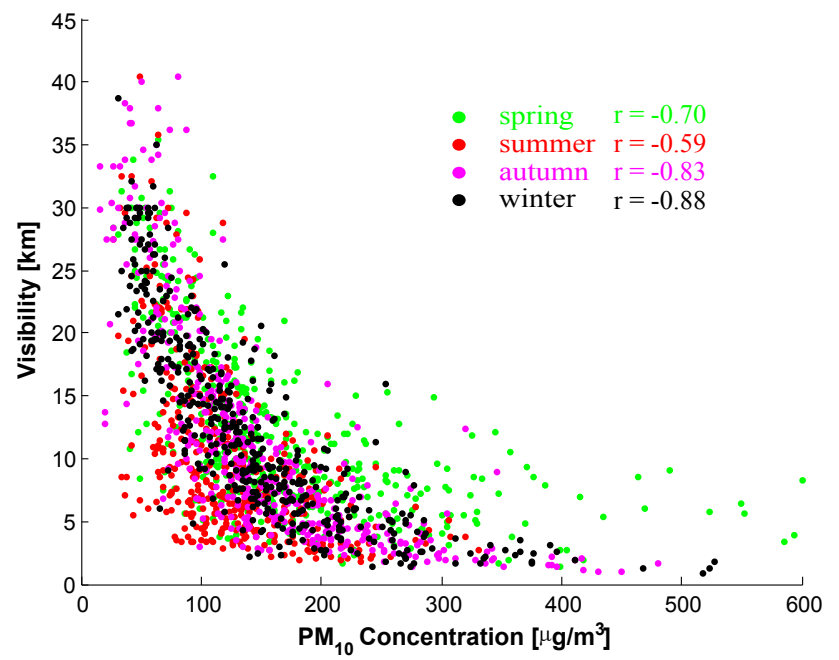

Fig. 5. Daily mean visibility of BCIA vs. daily mean $\mathrm{PM}_{10}$ concentration in Beijing from 2003 to 2007 using the 19 observing stations. The correlation index between visibility and $\ln \left(\mathrm{PM}_{10}\right.$ concentration) for four seasons is shown as the variable " $r$ ".

\subsection{Dependence of visibility on $\mathrm{PM}_{10}$ and meteorological conditions}

Several former studies indicated that the decrease of visibility was related to the increase of $\mathrm{PM}_{10}$ in urban city Xian and Taiwan (Che et al., 2006; Tsai, 2005). The daily mean visibility of BCIA in relation to daily mean $\mathrm{PM}_{10}$ mass concentration of Beijing from 2003 to 2007 is shown in Fig. 5. The days with daily mean $\mathrm{RH}$ greater than $90 \%$ are excluded from analysis (Malm and Day, 2001; Chang et. al., 2009). Daily average $\mathrm{PM}_{10}$ concentration in spring is higher than those in other seasons. The correlation index between visibility and $\ln \left(\mathrm{PM}_{10}\right.$ concentration) for four seasons are statistically significant at $99 \%$ confidence level. "Good day" hardly occur when $\mathrm{PM}_{10}$ concentration (index) is greater than $250 \mu \mathrm{g} \mathrm{m}^{-3}$ (150). The visibility may varies between $2 \mathrm{~km}$ and $45 \mathrm{~km}$ when $\mathrm{PM}_{10}$ concentration (index) is below $150 \mu \mathrm{g} \mathrm{m}^{-3}$ (100), and most of the days with visibility below $10 \mathrm{~km}$ occur in the summer due to the high RH (Fig. 4).

Figure 6 combined frequency distribution of visibility ranges and RH at BCIA from 1999 to 2007. Results show that low visibility is highly associated with high RH. Most "very bad" hours occur when the RH is $90 \sim 100 \%$. There are a few cases of "very bad" hours caused by sand storm when $\mathrm{RH}$ is about $20 \sim 40 \%$. For most hours with visibility higher than $2 \mathrm{~km}$ and lower than $10 \mathrm{~km}$, the RH is around $60 \sim 100 \%$. The RH has a broad range of $10 \sim 100 \%$ for visibility from $10 \mathrm{~km}$ to $15 \mathrm{~km}$, but with a high frequency around $30 \sim 40 \%$. Results also show that good visibility is highly related to low RH. For "good" hours with visibility equal or higher than $20 \mathrm{~km}$, the RH is mostly around $20 \sim 40 \%$. Results in this study are consistent with previous work that showed reduc-

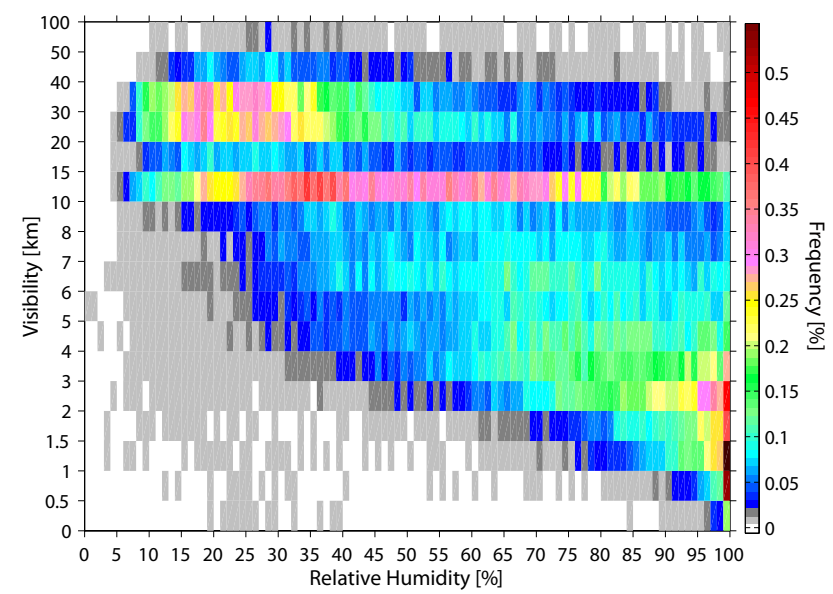

Fig. 6. Hourly occurrence frequency of visibility in relation to visibility and RH in BCIA from 1999 to 2007.

tion in visibility under high RH (Malm and Day, 2001; Sequiera and Lai, 1998).

To understand visibility variation at a location, it is important to examine the relationship between visibility and the winds that can characterize the transport of the pollutants. Figure 7 presents the visibility distribution in relation to wind direction and wind speed. It is obvious that the visibility over BCIA is low under the prevailing southerly, southeasterly and easterly wind conditions when industrial aerosols are carried over to Beijing (Song et al., 2006; Chan et al., 2005). Mountains around the north and west of Beijing play a significant role in blocking these urban aerosols from being advected out of Beijing. Moreover, "bad" hours occur under weak variable wind conditions; this may be related to the dominance of local urban emissions. There are some cases of lower visibility under strong southerly or southeasterly wind (greater than $12 \mathrm{~m} \mathrm{~s}^{-1}$ ) condition, which correspond to the low level jet under severe convective system in the summer. "Good" visibility is associated with northerly, northwesterly and westerly wind greater than $3 \mathrm{~m} \mathrm{~s}^{-1}$, suggesting that regional transport from less populated and moist air from northwestern China.

Although the annual $\mathrm{PM}_{10}$ concentration has been reported to decrease from 1999 to 2005 in Beijing (Chan and Yao, 2008), the increase of moisture over the years in the summer may intensify the hygroscopic growth of the aerosol particles, and therefore increase light extinction and reduce visibility. Specific humidity reveals an increasing rate of $0.16 \mathrm{~g} \mathrm{~kg}^{-1}$ per year in the summer from 1999 to 2007 (not shown). We think it is a probable explanation of the trend of decreasing visibility from 1999 to 2007. Surface moisture increase is also reported by Dai (2006) in a global range and is found to be associated with global warming. 


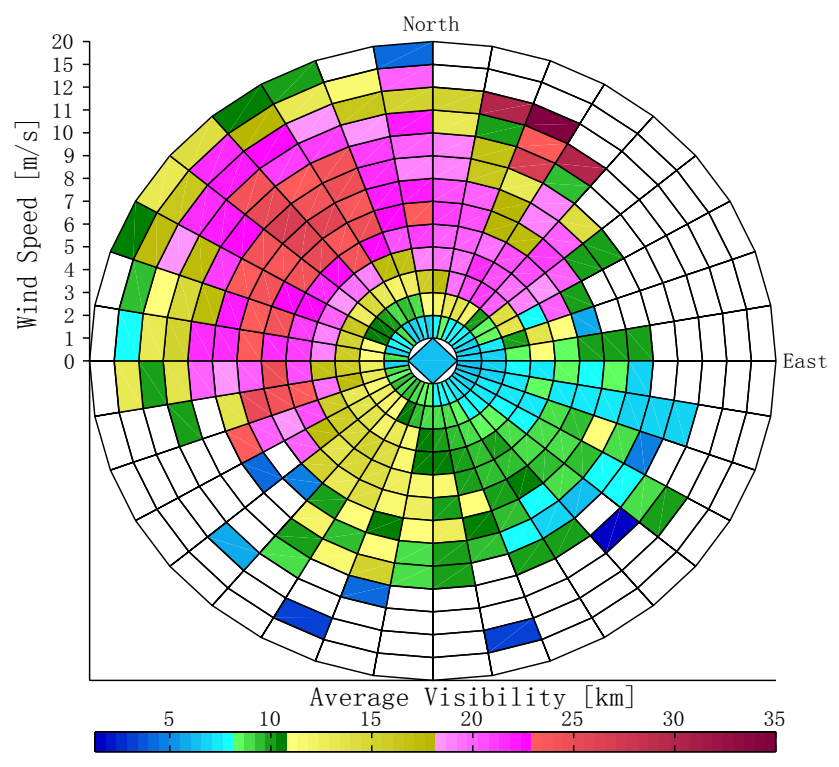

Fig. 7. Visibility distribution in relation to wind direction and wind speed in BCIA from 1999 to 2007.

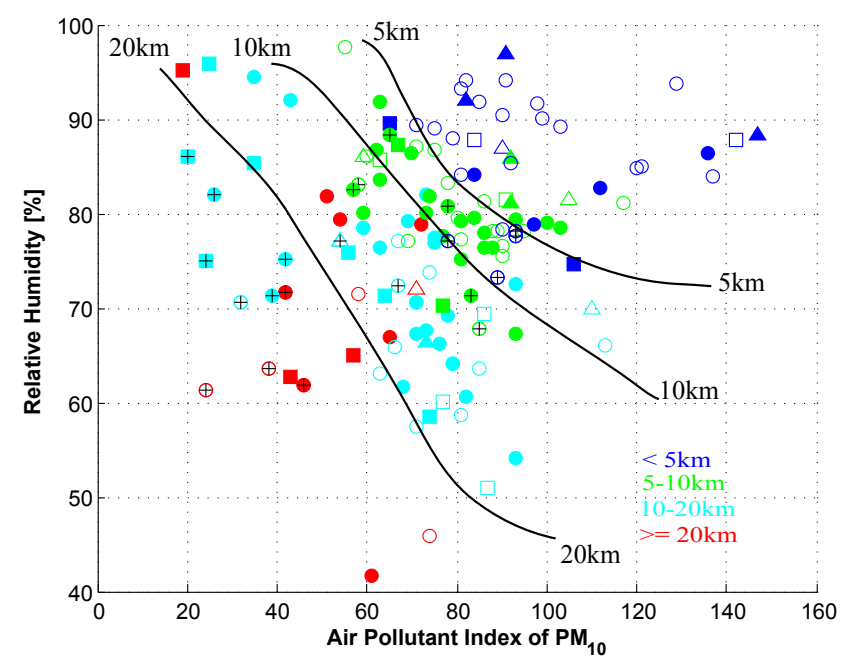

Fig. 8. Daily mean visibility distribution in relation to $\mathrm{RH}, \mathrm{PM}_{10}$ index, wind speed, and wind direction for August from 2003 and 2008 in Beijing. Blue symbol represents visibility lower than $5 \mathrm{~km}$, green symbol represents visibility lower than $10 \mathrm{~km}$ and no less than $5 \mathrm{~km}$, cyan symbol represents visibility lower than $20 \mathrm{~km}$ and no less than $10 \mathrm{~km}$, and red symbol represents visibility no less than $20 \mathrm{~km}$. The symbols with "+" represent observation in 2008. Triangle represents wind speed lower than $1.5 \mathrm{~m} \mathrm{~s}^{-1}$, circle represents wind speed greater than $1.5 \mathrm{~m} \mathrm{~s}^{-1}$ and lower than $3 \mathrm{~m} \mathrm{~s}^{-1}$, and square represents wind speed greater than $3 \mathrm{~m} \mathrm{~s}^{-1}$. Hollow symbols represent wind directions of south, southeast, east, and southwest. Solid symbols represent wind directions of northeast, north, northwest and west. The black solid lines denote the visibility contour of $5 \mathrm{~km}$, $10 \mathrm{~km}$ and $20 \mathrm{~km}$.

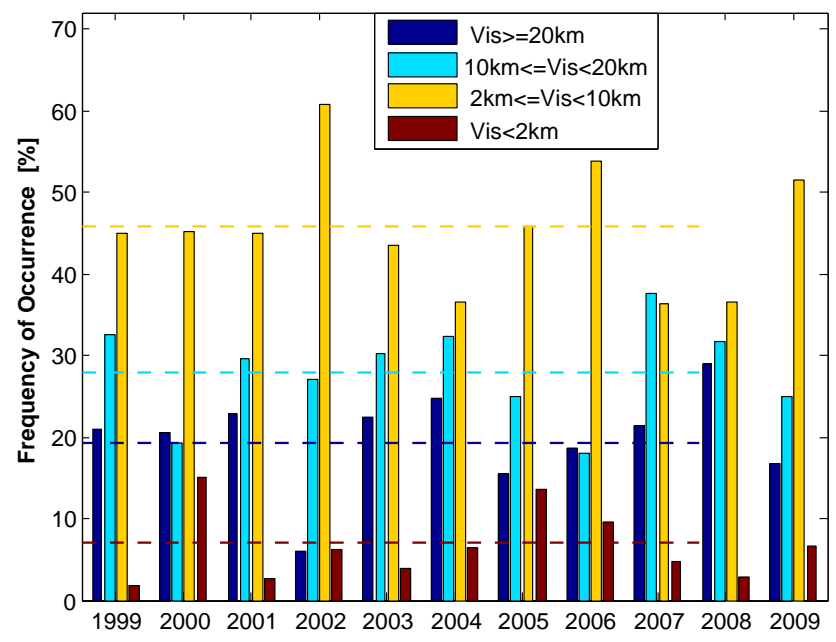

Fig. 9. Occurrence frequency of hourly visibility in different visual ranges from 8 to 24 August 1999 to 2009. Dashed lines show the average frequency of visibility from 8 to 24 August in different visual ranges from 1999 to 2007.

\subsection{Visibility in August}

Improvements in visibility have been experienced at UK after the reduction of pollution (Doyle and Dorling, 2002). During Beijing 2008 Olympics, the Chinese government had planned to increase Blue Sky frequency by limiting vehicle emission and other emission(Zhang et al., 2009). But how much the emission should be limited is an interesting question. Figure 8 summarizes the relationship of daily mean visibility with daily mean $\mathrm{RH}$ and $\mathrm{PM}_{10}$ index in August, which is the olympic month, from 2003 to 2007. Also observations in 2008 , represented by the symbols with "+", are shown in Fig. 8. Precipitation and fog days are excluded. It is seen that low visibility is generally associated with high $\mathrm{RH}$ and high $\mathrm{PM}_{10}$ index, while high visibility occurs when $\mathrm{RH}$ and $\mathrm{PM}_{10}$ index are low. The daily mean $\mathrm{RH}$ in August varies from $42 \%$ to $98 \%$, with an average of $78 \%$ during the years from 2003 to 2007. $\mathrm{PM}_{10}$ index in the same period varies from 15 to 150, with an average of 81. The averaged visibility in August from 2003 to 2007 is $9.7 \mathrm{~km}$. The increasing moisture or RH brought more challenge to improve visibility during Olympics 2008. Since the RH modification was impossible, a possible way to increase visibility was to reduce $\mathrm{PM}_{10}$ index. Assuming a RH of $78 \%$, Figure 8 shows that $\mathrm{PM}_{10}$ index needs to be 77 (44) in order to get a visibility of $10(20) \mathrm{km}$ during August. A recent study shows that $24 \%$ of $\mathrm{PM}_{10}$ in Beijing is contributed by vehicle emission in a wet season (Zhang et al., 2007). Other emissions, such as soil dust, coal combustion, secondary pollutants, biomass burning, and industrial emission also make 30\%, 19\%, 18\%, $9 \%$ and $1 \%$ contributions to $\mathrm{PM}_{10}$, respectively (Zhang et al., 2007). If the visibility would be $10 \mathrm{~km}$ under a RH of $78 \%, 30 \%$ of vehicle emissions should be limited for the 


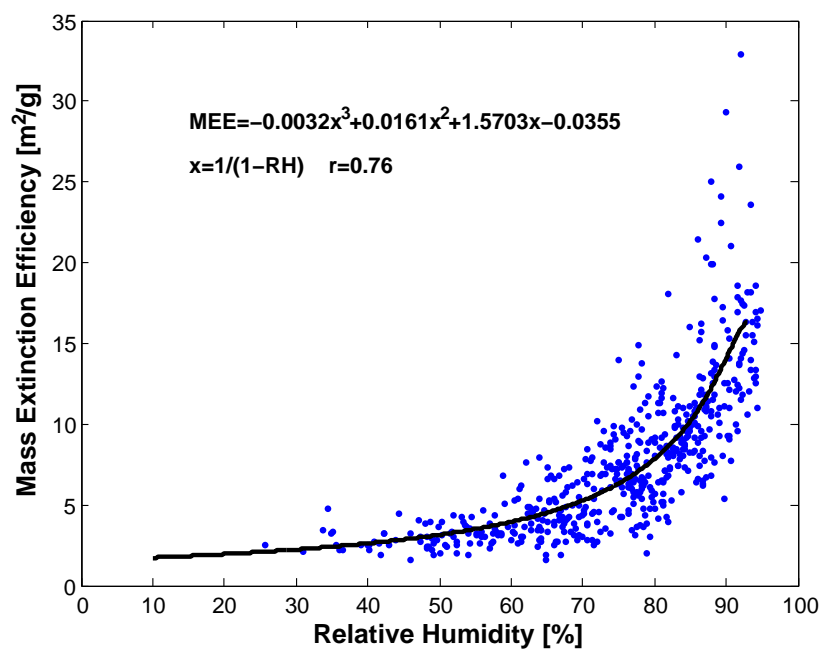

Fig. 10. The relationship between daily mean mass extinction efficiency (MEE) and relative humidity in summer 2003-2008. The black curve is the fitting line of the data. The correlation coefficient between MEE and $x$ is shown as the variable " $r$ ".

Olympics 2008. For RH higher than $60 \%$ in August, the visibility would not reach the standard of a "good" day even if all vehicles be limited. In addition to vehicle emission limitation, soil dust emission, coal combustion and secondary particulate should also be limited during the Olympics 2008 if the visibility is to be improved to $20 \mathrm{~km}$ in Beijing. In fact, Chinese government has reduced soil dust by planting vegetation and limited coal combustion and industrial emission during Olympics 2008 (Zhang et al., 2009). The symbols with "+" represent observation in the August of 2008. Figure 8 shows obvious decrease of daily $\mathrm{PM}_{10}$ index and increase of daily mean visibility in the August of 2008. The mean $\mathrm{PM}_{10}$ index in August 2008 has been reduced to 60. The mean visibility has been improved to $12.6 \mathrm{~km}$ in August of 2008 (Fig. 8). From the hour frequency in different visibility range in Fig. 9, blue sky hour rate had been increased 50.2\% from 8 to 24 August 2008, when Olympic game was held. In that period, the mean $\mathrm{PM}_{10}$ index was reduced to 53. Unfortunately, from 8 to 24 August 2009, the blue sky hour rate has been recovered to the average level from 1999 to 2007 . Although about $15 \%$ vehicle was limited for working day after Olympic Game in Beijing, it is not enough to improve blue sky rate obviously in August. The observed mean $\mathrm{PM}_{10}$ index is 76 and hourly mean visibility is $9.5 \mathrm{~km}$ in August of 2009 (not shown).

Although quantitatively dividing the impacts of relative humidity (RH) and aerosol on visibility during Olympic 2008 is interesting, it is still a complicated issue. The hygroscopic growth factor of aerosol varies with different chemical compositions and physical properties. However, longterm observation data of chemical species and size distribution of aerosol in Beijing is not available. If we assume that aerosol chemical composition and size distribution are relatively constant, especially in annual variation, we can roughly quantify the effect of $\mathrm{RH}$ and aerosol on visibility during 2008 Olympic.

An important parameter linking aerosol mass concentration with the light extinction is the mass extinction efficiency (MEE). It is defined as the ratio of the extinction coefficient to $\mathrm{PM}_{10}$ mass concentration ( $\mathrm{Si}$ et al., 2005; He, 2009). The light extinction is calculated from the Koschmieder's formula:

$\sigma_{\mathrm{ext}}=3.912 / \mathrm{V}$,

where $\sigma_{\text {ext }}$ is the extinction coefficient, and $V$ denotes visibility (in $\mathrm{km}$ ). The dependence of daily averaged MEE on daily mean RH is shown in Fig. 10. Assuming MEE is a function of RH: MEE $=f(\mathrm{RH})=a x^{3}+b x^{2}+c x+d$, where $x$ is $1 /(1-\mathrm{RH})$. We can get the fitting coefficients based on daily mean mass extinction efficiency (MEE) and RH in summer of 2003-2008 (Fig. 10).

$\mathrm{MEE}=-0.0032 x^{3}+0.0161 x^{2}+1.5703 x-0.0355$

Here the correlation coefficient between MEE and $x$ is 0.76 , which is statistically significant at the $99 \%$ confidence level.

If we set $\mathrm{PM}_{10}$ concentration as the mean value from 2003 to 2007, and let RH equal to the mean RH during August of 2008, we could get the visibility improvement due to $\mathrm{RH}$ from Eqs. (1) and (2). Similarly, the effect of $\mathrm{PM}_{10}$ on visibility during olympic 2008 can be derived. The proportion of $\mathrm{RH}$ and $\mathrm{PM}_{10}$ (aerosol) on improving visibility during $\mathrm{Au}$ gust of 2008 is about $24 \%$ and $76 \%$, respectively.

\section{Conclusions}

Temporal variation of visibility and its relay on meteorological condition over BCIA have been examined using the hourly visibility, RH and wind field data from 1999 to 2007. The daily mean $\mathrm{PM}_{10}$ index from 2005 to 2007 are also used to investigate the relationship between visibility and suspended particles in the air in Beijing city. About $47.8 \%$ (24.2\%) of the hours in Beijing are "bad" ("good") hours between 1999 and 2007. Summer is the season with the lowest visibility in a year, and 01:00 LT is the hour with lowest visibility in a day. Analysis of the meteorological conditions reveals that high (low) RH is in high accordance with low (high) visibility. A "good" hour in Beijing is associated with northerly, northwesterly, and westerly wind greater than $3 \mathrm{~m} \mathrm{~s}^{-1}$; a "bad" hour is associated with weak variable wind and wind from the south, the southeast, and the east.

The data presented in this paper indicate that there is a significant decreasing trend of visibility over BCIA in the summer from 1999 to 2007 . The decreasing trend is apparently due to the increase in $\mathrm{RH}$. If the mean RH $78 \%$ is considered, a "good" day would occur if $\mathrm{PM}_{10}$ index were reduced 
to 44 . Assuming $24 \%$ of $\mathrm{PM}_{10}$ in Beijing is contributed by vehicles, a "good" day would not happened during Olympics 2008 even if all vehicle emissions were eliminated. Apart from vehicle emission limitation, soil dust, coal combustion and biomass burning limitation should also be considered to improve visibility for Bejing Olympics 2008. And this conclusion was confirmed in the August of 2008 during Beijing Olympics and in the August of 2009 later. Due to high RH in summer, the challenge of improving visibility of Beijing remains.

\section{Supplementary material related to this article is available online at: http://www.atmos-chem-phys.net/10/7821/2010/ acp-10-7821-2010-supplement.pdf.}

Acknowledgements. This study is supported by Chinese National Science Foundation under Grant 40975059 and 40921160380 . We thank BCIA to allow us to access their data. We are deeply grateful to four referees and the editor for their helpful comments.

Edited by: M. Gauss

\section{References}

Bäumer, D., Vogel, B., Versick, S., Rinke, R., Möhler, O., and Schnaiter, M.: Relationship of visibility, aerosol optical thickness and aerosol size distribution in an ageing air mass over South-West Germany, Atmos. Environ., 42, 989-998, 2008.

Chan, C. K., and Yao, X.: Air pollution in mega cities in China, Atmos. Environ., 42, 1-42, 2008.

Chan, C. Y., Xu, X. D., Li, Y. S., Wong, K. H., Ding, G. A., Chan, L. Y., and Cheng, X. H.: Characteristics of vertical profiles and sources of $\mathrm{PM}_{2.5}, \mathrm{PM}_{10}$ and carbonaceous species in Beijing, Atmos. Environ., 39, 5113-5124, 2005.

Chang, D., Song, Y., and Liu, B.: Visibility trends in six megacities in China 1973-2007, Atmos. Res., 94, 161-167, 2009.

Che, H., Zhang, X., Li, Y., Zhou, Z., and Chen, Z.: Relationship between horizontal extinction coefficient and $\mathrm{PM}_{10}$ concentration in Xi' an, china, during 1980-2002, China Particuology, 4, 327-329, 2006.

Chen, L. W. A., Chow, J. C., Doddridge, B. G., Dickerson, R. R., Ryan, W. F., and Mueller, P. K.: Analysis of Summertime PM2. 5 and haze in the Mid-Atlantic Region, J. Air Waste Manage. Assoc., 53, 946-956, 2003.

Dai, A.: Recent climatology, variability, and trends in global surface humidity, J. Clim., 19, 3589-3606, 2006.

Dayan, U. and Levy, I.: The Influence of Meteorological Conditions and Atmospheric Circulation Types on $\mathrm{PM}_{10}$ and Visibility in Tel Aviv, J. Appl. Meteorol., 44, 606-619, 2005.

Doyle, M. and Dorling, S.: Visibility trends in the UK 1950-1997, Atmos. Environ., 36, 3161-3172, 2002.

Hauck, H., Berner, A., Frischer, T., Gomiscek, B., Kundi, M., Neuberger, M., Puxbaum, H., Preining, O., and AUPHEP-Team: AUPHEP- Austrian Project on Health Effects of Particulates General overview, Atmos. Environ., 38, 3905-3915, 2004.
He, X.: Aerosol surface observation and the application of MODIS AOD in $\mathrm{PM}_{10}$ evaluation, 28 pp., (in Chinese), Master dissertation of Peking University, 2009.

Lee, D. O.: Trends in summer visibility in London and southern England 1962-1979, Atmos. Environ, 17, 151-159,1983.

Malm, W. C. and Day, D. E.: Estimates of aerosol species scattering characteristics as a function of relative humidity, Atmos. Environ., 35, 2845-2860, 2001.

Qin, J. and Yang, L.: Variation characteristics of atmospheric aerosol optical depths and visibility in North China during 1980 1994, Atmos. Environ., 34, 603-609, 2000.

Pope, C. R., Burnett R. T., Thun M. J., Calle E. E., Krewski D.. K. Ito, and. Thurston G. D.: Lung cancer, cardiopulmonary mortality, and long-term exposure to fine particulate air pollution. J. Amer. Med. Assoc., 287, 1132-1141, 2002.

Samet, J., Dominii F. C., Coursac I., and Zeger S.: Fine particulate air pollution and mortality in $20 \mathrm{U}$. S. cities, 1987-1994, New England J. Med., 343, 1742-1749, 2000.

Sequeira, R. and Lai, K. H.: The effect of meteorological parameters and aerosol constituents on visibility in urban Hong Kong, Atmos. Environ., 32, 2865-2871, 1998.

Shi, Z., Shao, L., Jones, T. P., Whittaker, A. G., Lu, S., Berube, K. A., He, T., and Richards, R. J.: Characterization of airborne individual particles collected in an urban area, a satellite city and a clean air area in Beijing, 2001, Atmos. Environ., 37, 40974108, 2003.

Si, F. Q., Liu, J. G., Xie, P. H., Zhang, Y. J., Liu, W. Q., Kuze, H., Liu C., Lagrosas, N., and Takeuchi, N.: Determination of aerosol extinction coefficient and mass extinction efficiency by DOAS with a flashlight source, Chin. Phys., 14, 2360-2364, 2005.

Sloane, C. S.: Summertime visibility declines: meteorological influences, Atmos. Environ., 17, 763-774, 1983.

Sloane, C. S.: Meteorologically adjusted air quality trends: visibility, Atmos. Environ., 18, 1217-1229, 1984.

Song, Y., Zhang, M., and Cai, X.: PM $_{10}$ modeling of Beijing in the winter, Atmos. Environ., 40, 4126-4136, 2006.

Trijonis, J.: Visibility in the southwest-An exploration of the historical data base, Atmos. Environ., 13, 833-843, 1979.

Tsai, Y. I.: Atmospheric visibility trends in an urban area in Taiwan 1961-2003, Atmos. Environ., 39, 5555-5567, 2005.

Vautard, R., Yiou, P., and Van Oldenborgh, G. J.: Decline of fog, mist and haze in Europe over the past 30 years, Nat. Geosci., 2, 115-119, 2009.

Wang, K., Dickinson, R. E., and Liang, S.: Clear sky visibility has decreased over land globally from 1973 to 2007, Science, 323, 1468-1470, 2009.

Zhang, W., Guo, J. H., Sun, Y. L., Yuan H., Zhuang, G. S., Zhuang, Y. H., and Hao, Z. P.: Source apportionment for urban $\mathrm{PM}_{10}$ and $\mathrm{PM}_{2.5}$ in the Beijing area, Chin. Sci. Bull., 52, 608-615, 2007.

Zhang, X. Y., Wang, Y. Q., Lin, W. L., Zhang, Y. M., Zhang, X. C., Gong, S., Zhao, P., Yang, Y. Q., Wang, J. Z., and Hou, Q.: Changes of Atmospheric Composition and Optical Properties Over BEIJING-2008 Olympic Monitoring Campaign, Bull. Am. Meteorol. Soc., 90, 1633-1651, 2009. 